\title{
Efeito da iluminação constante sobre a placenta de ratas: um estudo morfológico, morfométrico e histoquímico
}

\author{
[The effect of constant illumination on the placenta in rats: a morphological, \\ morphometric and immunohistochemical study] \\ F.C.A. Silva, A.A.C. Teixeira, V.W. Teixeira \\ Universidade Federal Rural de Pernambuco - Recife, PE
}

\begin{abstract}
RESUMO
A presente pesquisa analisou o efeito da iluminação constante sobre a estrutura placentária de ratas, abordando parâmetros morfológicos, morfométricos e histoquímicos. Vinte ratas albinas foram submetidas aos seguintes tratamentos: $12 \mathrm{hL} / 12 \mathrm{hE}$ por 60 dias, e acasaladas em seguida (GI); ausência de luz por 60 dias, e acasaladas em seguida (GII); iluminação constante por 60 dias, e acasaladas em seguida (GIII); iluminação constante por 60 dias, acasaladas em seguida e tratadas com melatonina (GIV). O estímulo luminoso foi em torno de 400 lux. A melatonina foi administrada na água $(400 \mathrm{mg} / \mathrm{mL}$ de etanol). Os resultados mostraram que histologicamente o GII apresentou vacuolização das células do trofospongio. Morfometricamente, o GIII apresentou camada do labirinto com redução no número de trofoblastos sinciciais e maior vascularização materno-fetal, hiperplasia e hipertrofia das células trofoblásticas gigantes, uma maior média da área total do disco placentário; porém, na camada de trofospongio, as células trofoblásticas e trofoblastos sinciciais não diferiram nos grupos experimentais. As placentas do GIV foram semelhantes às do GI. Histoquimicamente não houve alterações nas fibras colágenas, elásticas, reticulares e glicosaminoglicanas ácidas. Em conclusão, a iluminação constante promove alterações morfológicas e morfométricas na placenta de ratas, podendo acarretar redução funcional e restrições ao crescimento fetal. Essas alterações são abolidas pela reposição de melatonina.
\end{abstract}

Palavras-chave: pineal, reprodução, prenhez, roedores, fotoperíodo

\begin{abstract}
This study examined the effect of constant illumination on the placental structure of rats, addressing morphological, morphometric and immunohistochemical parameters. 20 albino rats were subjected to the following treatments: GI-12hL/12hE for 60 days and then mated; GII-dark for 60 days and then mated; GIII- constant illumination for 60 days and then mated and GIV-constant light for 60 days, mated and then treated with melatonin. The light stimulus was around 400 lux. Melatonin was administered in water $(400 \mathrm{mg} / \mathrm{ml}$ ethanol). The results showed that GII had histologically trofospongio vacuolization of cells. Morphometrically, GIII presented a labyrinth layer reduction in the number of syncytial trophoblasts and greater maternal-fetal vasculature, hyperplasia and hypertrophy of trophoblast giant cells, a higher average of the total area of the placenta disk, but in the trofospongio layer, the trophoblast cells and syncytial trophoblasts did not differ between experimental groups. The placentas in GIV were similar to GI. Histochemically there were no changes in the collagen and elastic fibers, reticular and acidic glycosaminoglycans. In conclusion, the constant lighting promotes morphological and morphometric changes in the placenta in rats and may lead to functional reduction and restrictions on fetal growth. These changes are abolished by the melatonin replacement.
\end{abstract}

Keywords: pineal, reproduction, pregnancy, rodents, photoperiod

Recebido em 1 de junho de 2014

Aceito em 3 de março de 2015

E-mail: fcas14@hotmail.com 


\section{INTRODUÇÃO}

A melatonina é um neuro-hormônio, produzido pela glândula pineal, que apresenta concentrações baixas durante o dia e elevadas durante a noite (Pablos et al., 1996). Nos mamíferos, incluindo o ser humano, o ritmo de secreção da melatonina é gerado na fase de escuridão (Reiter, 2009) e cujo hormônio tem mostrado um papel chave na função reprodutiva tanto em animais sazonais como nos não sazonais, caracterizando-se pela regulação na produção de estrógeno e progesterona, inibição da contratilidade uterina, regulação da atividade funcional e crescimento ovariano, redução do estresse oxidativo em folículos ovarianos e diminuição de gonadotrofinas (GnRH) que regulam a concentração de FSH e LH (Graham et al., 2004).

A literatura relata que tanto a pinealectomia como iluminação constante, após um período de três meses, produzem alterações morfológicas nos ovários e útero. Quando ratas são submetidas à iluminação constante ou pinealectomizadas, desenvolvem ovários policísticos. Já no útero, estudos morfológicos mostraram hipertrofia do epitélio endometrial e áreas apresentando brotos celulares, estroma compacto, não edematoso, rico em fibras colágenas, e contendo poucas glândulas, as quais na maioria apresentam áreas de estratificação (Teixeira et al., 2002; Medeiros et al., 2003; Prata Lima et al., 2004; Teixeira et al., 2004).

Várias pesquisas têm demonstrado que as concentrações de melatonina no plasma aumentam durante a gestação, atingindo valores elevados no final desse período, sugerindo que esse hormônio desempenhe um importante papel na manutenção da gestação (Bishnupuri e Haldar, 2001; Nakamura et al., 2001). Nos mamíferos placentários, a implantação é considerada o ponto crítico da gravidez, pois o sucesso da gestação requer o desenvolvimento de uma interação sincronizada entre o endométrio e o blastocisto para o desenvolvimento da placenta (Cross et al., 1994).

No trato reprodutivo das ratas, os receptores de melatonina foram encontrados nos ovários e no estroma antimesometrial uterino (Soares Jr. et al., 2003). À medida que a decidualização do estroma uterino durante a gravidez avança, os sítios de ligação da melatonina são progressivamente reduzidos e se limita ao estroma antimesometrial. Alguns pesquisadores têm relatado que ratas pinealectomizadas ou submetidas à iluminação constante, quando acasaladas, apresentam redução no número de sítios implantados, relacionando tal efeito à interferência com o processo de ovulação (Soares et al., 2003; Dair et al., 2008). Porém, não há relatos dos possíveis efeitos do fotoperíodo sobre o desenvolvimento placentário. Assim, o objetivo do presente estudo foi analisar o efeito da iluminação constante sobre a estrutura placentária de ratas, abordando parâmetros morfológicos, morfométricos e histoquímicos.

\section{MATERIAL E MÉTODOS}

Foram utilizadas 20 ratas albinas (Rattus norvegicus albinus) com 90 dias de idade, procedentes do Biotério do Departamento de Morfologia e Fisiologia Animal, da Universidade Federal Rural de Pernambuco. As fêmeas foram mantidas em gaiolas, com alimentação e água ad libitum, temperatura de $22^{\circ} \mathrm{C}$ e iluminação artificial que estabeleceu um fotoperíodo de 12 horas claro e 12 horas escuro.

Após um período de adaptação, as fêmeas foram divididas, ao acaso, em quatro grupos, cada um constituído por cinco animais: Grupo I- ratas mantidas em ciclo claro/escuro de 12/12 horas por 60 dias, e acasaladas em seguida (controle); Grupo II- ratas mantidas em ausência de luz por 60 dias, e acasaladas em seguida; Grupo IIIratas mantidas em iluminação constante por 60 dias, e acasaladas em seguida; Grupo IV- ratas mantidas em iluminação constante por 60 dias, acasaladas em seguida e tratadas com melatonina.

Após a formação dos respectivos grupos, as ratas foram tratadas por 7 dias. $\mathrm{O}$ protocolo experimental foi aprovado pela Comissão de Ética institucional, de no ${ }^{\circ}$ 23082.009629/2010.

A ausência de luz foi obtida utilizando-se uma sala de aproximadamente $3 \mathrm{~m}^{2}$, totalmente vedada para não permitir a entrada de luz. O estímulo luminoso foi obtido utilizando-se uma caixa de madeira com área de $0,5 \mathrm{~m}^{3}$, com frestas para permitir a ventilação, contendo duas lâmpadas fluorescentes, marca PHILIPS, de 40W, as quais forneceram luminosidade adequada e suficiente, em torno de 400 lux. 
A melatonina ( $\mathrm{N}$-acetil-5-metoxi-triptamina) foi administrada à água dos bebedouros em frascos âmbar, das 18:00 às 6:00 horas, aos animais do grupo IV, após confirmação do acasalamento. Durante o dia foi feita restrição à água (Trentini et al., 1992). A solução de melatonina foi preparada diariamente dissolvendo-se $400 \mathrm{mg}$ de melatonina cristalina (Sigma ChemicalCo., St. Louis, Mo., USA) em $1 \mathrm{~mL}$ de etanol absoluto, e essa solução diluída posteriormente em um litro de água de torneira. Às ratas dos grupos GI, GII e GIII foi administrada a mesma concentração de solução de etanol na água dos bebedouros.

Após 60 dias do início do experimento, as fêmeas de todos os grupos foram acasaladas na proporção de um macho para três fêmeas, sempre no início da noite (18:00h). Na manhã do dia seguinte, sempre às $06: 00 \mathrm{~h}$, foram realizados exames colpocitológicos para a confirmação do acasalamento, tomando-se com parâmetro a presença de espermatozoides nos esfregaços vaginais. Para a colheita da secreção vaginal, foram utilizadas hastes de algodão umedecidas em solução salina. Logo após a colheita, foi feito um esfregaço em lâminas histológicas através de um movimento rotatório da haste. Essas lâminas foram imediatamente mergulhadas numa mistura de álcool-éter em partes iguais e, em seguida, coradas pelo método Shorr-Harris.

Para a análise morfológica e histoquímica, cinco fêmeas de cada grupo foram eutanasiadas no décimo quarto dia de gestação. Para tanto, as fêmeas foram anestesiadas com hidrocloridrato de cetamina $(80 \mathrm{mg} / \mathrm{kg})$ e xilazina $(6 \mathrm{mg} / \mathrm{kg})$ por via intramuscular. Em seguida, foi realizada a abertura da cavidade abdominal para remoção total dos cornos uterinos, os quais foram mergulhados imediatamente em líquido de Bouin, permanecendo no mesmo por 48 horas. Após esses procedimentos, as placentas foram clivadas, obtendo-se fragmentos, os quais foram submetidos à técnica de inclusão com parafina. A seguir, os blocos foram cortados em micrótomo do tipo Minot (Leica ${ }^{\circledR}$ RM 2035), ajustado para $3 \mu \mathrm{m}$. Os cortes assim obtidos foram colocados em lâminas previamente untadas com albumina de Mayer e mantidos em estufa regulada à temperatura de $37^{\circ} \mathrm{C}$, durante 24 horas, para secagem e colagem. Em sequência, os cortes foram submetidos à técnica de coloração pela Hematoxilina-Eosina (H.E), analisados em microscópio de luz, da marca OLYMPUS ${ }^{\circledR} \mathrm{BX}$ 49, e fotografados em fotomicroscópio OLYMPUS $^{\circledR}$ BX-50. Para histoquímica da matriz placentária, utilizou-se o tricromico de Mallory (fibras colágenas), Orceína (fibras elásticas), Impregnação argêntica (fibras reticulares) e Alcian blue $\mathrm{pH}$ 2,5 (glicosaminoglicanas ácidas). As reações de colorações foram classificadas como intensa $(++)$, moderada $( \pm)$ e fraca $(+)$

Para a morfometria do disco placentário, realizou-se a captura de imagens por meio de câmera de Vídeo Sony ${ }^{\circledR}$, acoplada ao microscópio, as quais foram submetidas ao aplicativo Morfometria de Linhas, calibrado em micrômetros, associado ao do programa ImagemLab 2000 para Windows. Na captura, foram utilizadas cinco lâminas de cada grupo, sendo medidos cinco campos em cada disco placentário. Além disso, utilizou-se uma ocular integradora, segundo a metodologia de Souza et al. (2003), contendo 100 pontos distribuídos geometricamente. A ocular integradora foi acoplada a um microscópio de luz com objetiva de 40x.

O retículo da ocular integradora foi projetado sobre os cortes histológicos, os quais possibilitou a contagem dos pontos que incidiram nas camadas da placenta. Com a finalidade de evitar vícios de contagem sobre os campos comuns em um mesmo corte, foi feita a leitura sempre num mesmo sentido, ou seja, da esquerda para direita. Em cada lâmina foram contados 10 campos aleatórios, com quatro repetições, perfazendo um total de 1.000 pontos por lâmina, sendo quantificados os seguintes parâmetros: Na região do labirinto: 1- Trofoblasto sincicial, 2- Vasos fetais e 3- Vasos maternos. $\mathrm{Na}$ região do trofospongio/células trofoblásticas gigantes: 1Células trofoblásticas, 2- Trofoblasto sincicial e 3- Células trofoblásticas gigantes.

A análise estatística foi realizada por meio de métodos não paramétricos de Kruskal-Wallis, por meio dos quais se obtiveram as médias e desvio padrão de cada grupo, os quais foram comparadas pelo teste de Wilcoxon-MannWhitney, a 95\% de significância. 


\section{RESULTADOS}

$\mathrm{Na}$ análise morfológica das placentas das ratas mantidas em ciclo claro/escuro de 12/12 horas por 60 dias, e acasaladas em seguida (controle), observaram-se a presença da região da decídua bastante vascularizada e a região do disco placentário bem desenvolvido, com as três camadas: camada do labirinto, região mais externa e a mais espessa, caracterizada pela presença de numerosas lacunas contendo vasos maternos e fetais. Na camada do trofospôngio observaram-se trofoblastos indiferenciados. A última camada é formada pelas células trofoblásticas gigantes, as quais se misturam com a decídua (Fig. 1A, B, C, D).

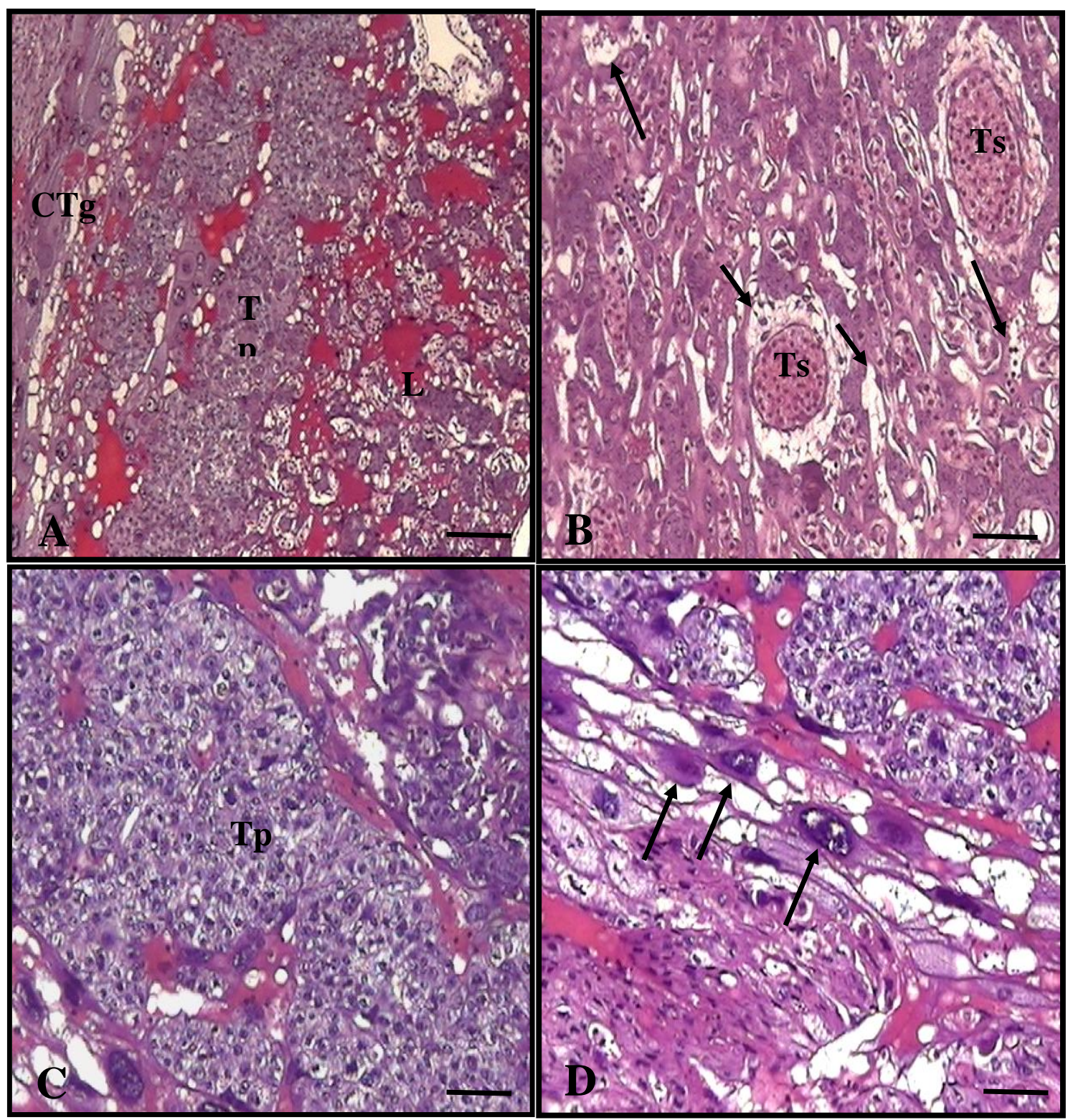

Figura 1. Rata. A- Disco placentário do grupo I: labirinto (L), trofospôngio (Tp) e Célula trofoblástica gigante $(\mathrm{CTg})$. Barra $=200 \mu \mathrm{m}$. B- Labirinto contendo vasos maternos (setas curtas), vasos fetais (setas longas) e Trofoblasto sincicial (Ts). Barra $=100 \mu \mathrm{m}$. C e D- Detalhe do trofospôngio (Tp) e células trofoblásticas gigantes (setas), respectivamente. Barras $=25 \mu \mathrm{m}$. Coloração H.E. 
Nas ratas mantidas em ausência de luz por 60 dias, e acasaladas em seguida, observou-se também a região da decídua vascularizada e, no disco placentário, as regiões do labirinto e trofospôngio apresentaram as mesmas características observadas nas ratas mantidas em ciclo claro/escuro de 12/12 horas por 60 dias, e acasaladas em seguida (controle). No entanto, foi observada vacuolização das células do trofospôngio (Fig. 2A). Nas ratas mantidas em iluminação constante por 60 dias, e acasaladas em seguida, de modo geral, as características morfológicas das placentas foram semelhantes aos das ratas mantidas em ciclo claro/escuro de 12/12 horas por 60 dias, e acasaladas em seguida (controle), e aos das ratas mantidas em ausência de luz por 60 dias, e acasaladas em seguida, diferindo, no entanto, pelo fato de as ratas mantidas em iluminação constante por 60 dias, e acasaladas em seguida, apresentarem a camada do labirinto mais vascularizada, além das células trofoblásticas gigantes bastante desenvolvidas, com núcleos volumosos assumindo um caráter hipertrófico (Fig. 2B, C). As características morfológicas das placentas das ratas mantidas em iluminação constante por 60 dias, acasaladas em seguida e tratadas com melatonina foram semelhantes às observadas no grupo I (Fig. 2D)

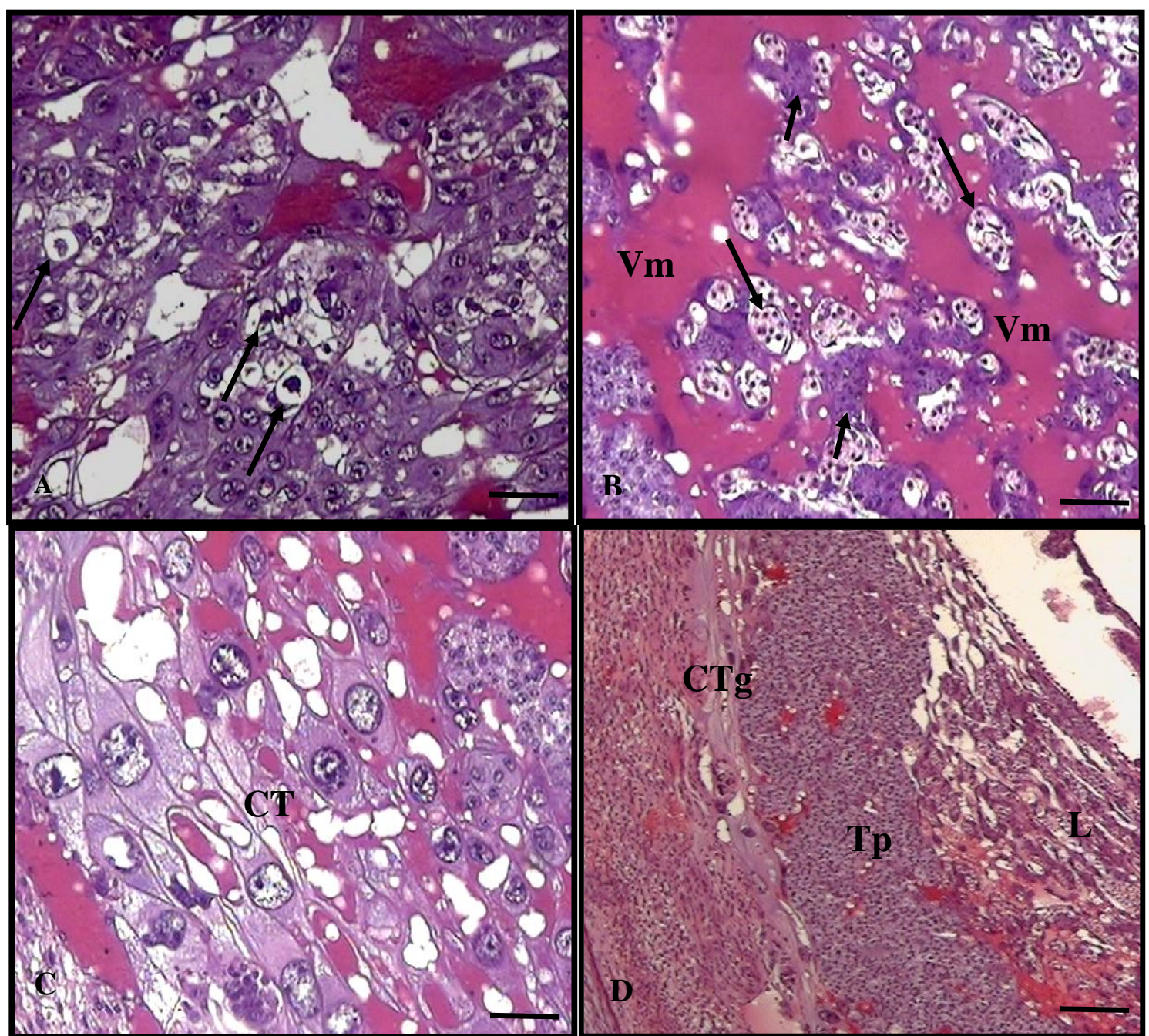

Figura 2. Rata. Grupo II e demais grupos. A- Trofospôngio (grupo II): células apresentando acentuada vacuolização (setas). Barra $=25 \mu \mathrm{m}$. B- Labirinto (grupo III): vasos maternos $(\mathrm{Vm})$, vasos fetais (setas longas) e Trofoblasto sincicial (Ts). Barra $=100 \mu \mathrm{m}$. C- Células trofoblásticas gigantes $(\mathrm{CTg})$ apresentando hipertrofia. Barra $=25 \mu \mathrm{m}$. D- Disco placentário (grupo IV): labirinto (L), trofospôngio (Tp) e células trofoblásticas gigantes $(\mathrm{CTg})$ com morfologia semelhante ao controle. Barra $=200 \mu \mathrm{m}$. Coloração H.E. 
A análise histoquímica não revelou alterações nos parâmetros fibras colágenas, elásticas, reticulares e glicosaminoglicanas ácidas (GAGs) (Tab. 1).

A análise estatística das médias da área total do disco placentário mostrou que as ratas mantidas em iluminação constante por 60 dias, e acasaladas em seguida, apresentaram a maior média, diferindo significativamente dos outros grupos experimentais, os quais não diferiram entre si (Tab. 2).
Nesse grupo também foram evidenciadas diferenças significativas nos parâmetros trofoblastos sinciciais e vascularização materna e fetal na região do labirinto (Tab. 3).

Assim como o aumento no número de células trofoblásticas gigantes (Hiperplasia) (Tab. 4). Na camada de trofospôngio, as células trofoblásticas e trofoblastos sinciciais não diferiram nos grupos experimentais.

Tabela 1. Histoquímica do disco placentário nos grupos experimentais. Reação intensa (++), moderada $( \pm)$ e fraca (+). Grupo I- ratas mantidas em ciclo claro/escuro de 12/12 horas por 60 dias, e acasaladas em seguida (controle); Grupo II- ratas mantidas em ausência de luz por 60 dias, e acasaladas em seguida; Grupo III- ratas mantidas em iluminação constante por 60 dias, e acasaladas em seguida; Grupo IV-ratas mantidas em iluminação constante por 60 dias, acasaladas em seguida e tratadas com melatonina. GAGs glicosaminoglicanas ácidas

\begin{tabular}{lcccc} 
& GI & GII & GIII & GIV \\
\hline Fibras colágenas & ++ & ++ & ++ & ++ \\
Fibras elásticas & + & + & + & + \\
Fibras reticulares & \pm & \pm & \pm & \pm \\
GAGs ácidas & + & + & + & + \\
\hline
\end{tabular}

Tabela 2. Média ( $\mu \mathrm{m})$ e desvio padrão da área total do disco placentário nos grupos experimentais. Grupo I- ratas mantidas em ciclo claro/escuro de 12/12 horas por 60 dias, e acasaladas em seguida (controle); Grupo II- ratas mantidas em ausência de luz por 60 dias, e acasaladas em seguida; Grupo III- ratas mantidas em iluminação constante por 60 dias, e acasaladas em seguida; Grupo IV- ratas mantidas em iluminação constante por 60 dias, acasaladas em seguida e tratadas com melatonina

\begin{tabular}{ccccc}
\hline GI & GII & GIII & GIV & F $^{P}$ \\
\hline $694,45 \pm 26,87 \mathrm{a}$ & $745,55 \pm 19,72 \mathrm{a}$ & $871,40 \pm 56,31 \mathrm{~b}$ & $622,63 \pm 53,44 \mathrm{a}$ & $5,402^{0,0029}$
\end{tabular}

*Médias seguidas pela mesma letra não diferem significativamente entre si pelo teste de Wilcoxon-Mann-Whitney $(\mathrm{P}>0,05)$.

Tabela 3. Média e desvio padrão dos elementos constituintes da região do labirinto do disco placentário nos grupos experimentais. Grupo I- ratas mantidas em ciclo claro/escuro de 12/12 horas por 60 dias, e acasaladas em seguida (controle); Grupo II- ratas mantidas em ausência de luz por 60 dias, e acasaladas em seguida; Grupo III- ratas mantidas em iluminação constante por 60 dias, e acasaladas em seguida; Grupo IV- ratas mantidas em iluminação constante por 60 dias, acasaladas em seguida e tratadas com melatonina

\begin{tabular}{cccccc}
\hline & GI & GII & GIII & GIV & $\mathrm{F}^{\mathrm{P}}$ \\
\hline $\mathrm{VM}$ & $0,19 \pm 0,16 \mathrm{a}$ & $0,16 \pm 0,18 \mathrm{a}$ & $1,61 \pm 1,16 \mathrm{~b}$ & $0,22 \pm 0,25 \mathrm{a}$ & $4,95^{0,0128}$ \\
VF & $44,66 \pm 4,44 \mathrm{a}$ & $44,22 \pm 3,40 \mathrm{a}$ & $50,53 \pm 7,75 \mathrm{~b}$ & $41,36 \pm 4,38 \mathrm{a}$ & $32,38^{0,0001}$ \\
TS & $53,91 \pm 4,32 \mathrm{a}$ & $52,50 \pm 2,93 \mathrm{a}$ & $44,31 \pm 4,27 \mathrm{~b}$ & $50,97 \pm 1,03 \mathrm{a}$ & $70,52^{0,0001}$ \\
\hline
\end{tabular}

*Médias seguidas pela mesma letra não diferem significativamente entre si pelo teste de Wilcoxon-MannWhitney $(\mathrm{P}>0,05)$. $\mathrm{VM}=$ vasos maternos; $\mathrm{VF}=$ vasos fetais e $\mathrm{TS}=$ trofoblasto sincicial. 
Tabela 4. Média e desvio padrão dos elementos constituintes da região do trofospôngio e células trofoblásticas gigantes. Grupo I- ratas mantidas em ciclo claro/escuro de 12/12 horas por 60 dias, e acasaladas em seguida (controle); Grupo II- ratas mantidas em ausência de luz por 60 dias, e acasaladas em seguida; Grupo III- ratas mantidas em iluminação constante por 60 dias, e acasaladas em seguida; Grupo IV- ratas mantidas em iluminação constante por 60 dias, acasaladas em seguida e tratadas com melatonina

\begin{tabular}{cccccc}
\hline & GI & GII & GIII & GIV & \multicolumn{1}{c}{$\mathrm{F}^{\mathrm{P}}$} \\
\hline CT & $10,91 \pm 1,30 \mathrm{a}$ & $9,58 \pm 0,96 \mathrm{a}$ & $10,34 \pm 1,87 \mathrm{a}$ & $8,85 \pm 3,62^{\mathrm{a}}$ & $2,615^{0,0869}$ \\
TS & $0,82 \pm 0,23 \mathrm{a}$ & $0,95 \pm 0,40 \mathrm{a}$ & $1,08 \pm 0,36 \mathrm{a}$ & $1,23 \pm 0,04^{\mathrm{a}}$ & $6,101^{0,0657}$ \\
CTG & $7,85 \pm 0,40 \mathrm{a}$ & $6,35 \pm 3,60 \mathrm{a}$ & $13,26 \pm 0,25 \mathrm{~b}$ & $8,57 \pm 2,17 \mathrm{a}$ & $17,052^{0,0001}$ \\
\hline
\end{tabular}

*Médias seguidas pela mesma letra não diferem significativamente entre si pelo teste de Wilcoxon-MannWhitney $(\mathrm{P}>0,05)$. $\mathrm{CT}=$ células trofoblástica; $\mathrm{TS}=$ trofoblasto sincicial e $\mathrm{CTG}=$ célula trofoblástica gigante

\section{DISCUSSÃO}

Os resultados da presente pesquisa mostraram alterações apenas nos aspectos morfológicos e morfométricos nas placentas das ratas submetidas à iluminação constante antes e durante a prenhez, e que a reposição oral da melatonina evita tais efeitos. No entanto, a ausência de luz produziu nas placentas uma acentuada vacuolização nas células do trofospôngio, indicando um processo degenerativo (Dair et al., 2008). Isso implica que a exposição à ausência de luz antes e durante a gestação pode resultar em danos reprodutivos, pois o trofospôngio, durante a formação da placenta corioalantoica, localiza-se na parte externa da placenta em contato com o endométrio, dando origem a sinciciotrofoblasto e células trofoblásticas gigantes, as quais são importantes para crescimento e manutenção placentária (Kanashiro et al., 2009). Adicionalmente podemos mencionar ainda que o peso da glândula pineal e níveis de melatonina, que são elevados em fêmeas de ratas não prenhas, diminuem acentuadamente durante $o$ início da concepção, aumentando gradualmente até o final da gestação, e, em seguida, atingindo níveis bastante elevados na proximidade do parto. Esse fato sugere o estabelecimento de uma relação inversa antes da gravidez, seguida por atividade moderada alta com uma correlação positiva durante a gravidez e súbito aumento na atividade da glândula pineal durante o parto (Haldar e Yadav, 2006). Os aspectos morfológicos e morfométricos observados nas células trofoblásticas gigantes das placentas dos animais do grupo III podem estar relacionados com o fato de que, quando ratas são submetidas à pinealectomia ou iluminação constante, apresentam baixos níveis de melatonina na corrente sanguínea e consequentemente maior ação dos hormônios estrógenos e andrógenos (Prata Lima et al., 2004; Tamura et al., 2008; Teixeira et al., 2004), que estimulam a diferenciação morfológica e funcional do trofoblasto (Sutherland, 2003) durante a gestação, pois, na ausência de luz, o aumento da melatonina na corrente sanguínea é responsável por inibir a sinalização de cAMP via receptor MT1, reduzindo, assim, os níveis estrogênicos na placenta e consequentemente diminuindo o desenvolvimento das células trofoblásticas gigantes (Von Gall et al., 2002). Em contrapartida, na iluminação constante há elevação nos níveis estrogênicos, estimulando a expressão dos genes $\mathrm{PL}$ - 2, via aumento de cAMP, o que também explicaria o maior desenvolvimento da camada de células trofoblásticas gigantes no disco placentário, em ratas submetidas à iluminação constante (Borski et al., 2002).

Com relação à evidência morfométrica da maior vascularização no labirinto do disco placentário das ratas do grupo III, sabe-se que o período peri-implantação em mamíferos é caracterizado por alterações morfológicas e funcionais no útero, acompanhadas de remodelação vascular denominada de angiogênese. Este último evento é importante para os processos de proliferação no útero e é necessário para o desenvolvimento tanto da placenta quanto dos embriões, e tem o fator de crescimento endotelial vascular (VEGF) como o principal responsável pela regulamentação de mudanças vasculares (Breier et al., 1992; Klauber et al., 1997; Risau, 1997). 
Estudos relataram que a melatonina em concentrações farmacológicas pode suprimir o RNAm do VEGF e consequentemente promover um declínio na produção desse fator (Lissoni et al., 2001; Lopes et al., 2003), sugerindo que o hormônio da pineal pode controlar e agir como uma molécula antiangiogênica natural.

Segundo Tamura et al. (2008), a melatonina pode atuar durante a gestação por diversos caminhos, desempenhando funções como modulador do ritmo circadiano e endócrino, imunomodulador e antioxidante, fatores que parecem ser essenciais para uma gestação bemsucedida. Porém, em nosso estudo, foi demonstrado que a exposição à iluminação constante promove aumento na espessura e vascularização da placenta, sugerindo um amadurecimento precoce desse órgão, pois na clínica humana o aumento da espessura e vascularização, dentre outros fatores, são indícios do amadurecimento placentário, como parte de um processo natural, contudo devem ser distinguidas das patologias, pois modificações macroscópicas e microscópicas têm sido associadas a gestações complicadas, principalmente no parâmetro espessura, sugerindo uma relação entre a precocidade placentária e o declínio de sua função (Resnik, 2002).

\section{CONCLUSÕES}

Assim, podemos concluir que a iluminação constante promove alterações morfológicas e morfométricas na placenta de ratas, podendo acarretar redução funcional e consequentemente restrições ao crescimento fetal. Essas alterações podem ser abolidas pela reposição de melatonina.

\section{AGRADECIMENTOS}

À Coordenação de Aperfeiçoamento de Pessoal de Nível Superior (CAPES) pela concessão da bolsa de mestrado.

\section{REFERÊNCIAS}

BISHNUPURI, K.S.; HALDAR, C. Maternal transfer of melatonin alters tho growth and sexual maturation of young Indian palm squirrel Funambuluspennanti. Biol. Signais Recent, v.10, p.317-325, 2001.
BORSKI, R.J.; HYDE, G.N.; FRUCHTMAN, S. Signal transduction mechanisms mediating rapid, nongenomic effects of cortisol on prolactin release. Steroids, v.67, p.539-548, 2002.

BREIER, G.; ALBRECHT, S.; RISAU, W. Expression of vascular endothelial growth factor during embryonic angiogenesis and endothelial cell differentiation. Development, v.114, p.521532, 1992.

CROSS, J.C.; WERB, Z.; FISHER, S.J. Implantation and placenta: key pieces of the development puzzle. Science, v.266, p.15081518, 1994.

DAIR, M.; CUI, P.; YU, M. et al. Melatonin modulates the expression of VEGF and HIF-1 $\alpha$ induced by $\operatorname{cocl}_{2}$ in cultured cancer cells. $J$. Pineal Res., v.44, p.121-126, 2008.

GRAHAM, L.H.; SWANSON, W.F.; WILAT, D.E.; BROWN, J.L. Influence of oral melatonin on natural and gonadotrophin- induced ovarian function in the domestic cat. Theriogenology, v.61, p.1061-1076, 2004.

HALDAR, C.; YADAV, R. Melatonin, gestation and fetal development. J. Endocrinol. Reprod., v.10, p. 42-42, 2006.

KANASHIRO, C.; SANTOS, T.C.; MIGLINO, M.A. et al. Growth and development of the placenta in the capybara (Hydrochaerishydrochaeris). Reprod. Biol. Endocrinol., v.7, p.1-13, 2009.

KLAUBER, N.; ROHAN, R.M.; FLYNN, E.; D'AMATO, R.J. Critical components of the female reproductive pathway are suppressed by the angiogenesis inhibitor AGM-1470. Nat. Med., v.3, p.443-446, 1997.

LISSONI, P.;ROVELLI, F.;MALUGANI, F. et al. Anti-angiogenic activity of melatonin in advanced cancer patients. Neuro Endocrinol. Lett., v.22, p.45-47, 2001.

LOPES, F.L.; DESMARAIS, J.; GÉVRY, N.Y. et al. Expression of vascular endothelial growth factor isoforms and receptors Flt-1 and KDR during the peri-implantation period in the mink. Mustelavison. Biol. Reprod., v.68, p.1926-1933, 2003. 
MEDEIROS, J.P.; WANDERLEY-TEIXEIRA, V.; TEIXEIRA, A.A.C. et al. Ultrastructural analisis of pineal ectomy and lack of light influence over collagen in the endometrium of rats. Int. J. Morphol., v.21, p.230-235, 2003.

NAKAMURA, Y.; TAMURA, H.; KASHIDA, S. et al. Changes of serum melatonin level and its relationship to feto-placental unit during pregnancy. J. Pineal Res., v.30, p.29-33, 2001.

PABLOS, M.I.; AGAPITO, M.T.; GUTIERREZBARAJA, R. et al. Effect of caicium on melatonin secretion in chick pineal gland I. Neuroscience., v.21, p.161-164, 1996.

PRATA LIMA, M.F.; BARACAT, E.C.; SIMÕES, M.J. Effects of melatonin on the ovarian response to pinealectomy or continuous light in female rats: similarity with polycystic ovary syndrome. Braz. J. Med. Biol. Res., v.37, p.987-995, 2004.

REITER, R.J.; DUN-XIAN, T.; MANCHESTER, L.C. et al. Melatonin and reproduction revisited. Biol. Reprod., v.81, p.445-456, 2009.

RESNIK, R. Intrauterine growth restriction. Am. Coll. Obstetric Gynecol., v.99, p.490-496, 2002.

RISAU, W. Mechanisms of angiogenesis. Nature, v.386, p.671-674, 1997.

SOARES JR, J.M.; MASANA, M.I.; ERSAHIN, C.; DUBOCOVICH, M.L. Functional melatonin receptors in rat ovaries at various stages of the estrous cycle. J. Pharmacol. Exp. Ther., v.306, p.694-702, 2003a.

SOARES JR, J.M.; SIMÕES, M.J.; OSHIMA, C.T. et al. Pinealectomy changes rat ovarian interstitial cell morphology and decreases progesterone receptor expression. Gynecol. Endocrinol., v.17, p.115-123, 2003b.
SUTHERLAND, A. Mechanism of implantation in the mouse: differentiation and functional importance of trophoblast giant cell behavior. Develop. Biol., v.258, p.241-251, 2003.

SOUZA, G.N.; CORDIOLI, E.; SIMÕES, M.J. et al. Alterações morfólogicas na contagem de fibras colágenas induzidas pela hialuronidase no colo de ratas prenhas. Rev. Bras. Ginecol., v.25, p.249-254, 2003.

TAMURA, H.; NAKAMURA, Y.; PILAR TERRON, M. et al. Melatonin and pregnancy in the human. Reprod. Toxicol., v.25, p.291-303, 2008.

TEIXEIRA, A.A.C.; SIMÕES, M.J.; EVÊNCIONETO, J.; WANDERLEY-TEIXEIRA, V. Morphologic aspects of endometrium, in the estrus phase, of pinealectomized rats. Int. J. Morphol., v.20, p.145-149, 2002.

TEIXEIRA, A.A.C.; SIMÕES, M.J.; WANDERLEYTEIXEIRA, V.; SOARES JR, J.M. Evaluation of the implantation in pinealectomized and/or submited to the constant illumination rats. Int. J. Morphol., v.22, p.189-194, 2004.

TRENTINI, G.P.; GENAZZANI, A.R.; CRÍSCUOLO, M. et al. Melatonin treatment delays reprodutive aging of female rat via the opiatergic system. Neuroendocrinol., v.56, p.364-370,1992.

VON GALL, C.; STEHLE, J.H.; WEAVER, D.R. Mammalian melatonin receptors: molecular biology and signal transduction. Cell Tissue Res., v.309, p.151-62, 2002. 